\title{
Variability of waiting times for the 4 most prevalent cancer types in Ontario: a retrospective population-based analysis
}

\author{
Amir Rastpour PhD, Mehmet A. Begen PhD, Alexander V. Louie MD PhD, Gregory S. Zaric PhD
}

Abstract

Background: Longer waiting times in cancer care are associated with lower care quality and wait-related patient dissatisfaction. We analyzed the variability and median of waiting times from when a patient seeks care to first treatment for the 4 most prevalent cancer types in Ontario.

Methods: Using retrospective health administrative data, we identified patients with a new diagnosis of prostate, breast, lung or colorectal cancer in Ontario between 2002 and 2012. Treatment interventions were categorized as chemotherapy, radiotherapy or surgery. We used regression analyses to calculate trends for the coefficient of variation, the Gini coefficient and the median waiting time for each cancer type-treatment type pair over the study period.

Results: During the study period, 95501 new cases of prostate cancer, 89244 breast cancer cases, 82604 lung cancer cases and 80761 colorectal cancer cases were registered. The coefficient of variation and the Gini coefficient of waiting times decreased for all cancer type-treatment type pairs (except for the Gini coefficient for breast cancer-radiotherapy) over the study period. However, both decreasing and increasing trends in median waiting times were observed across cancer type-treatment type pairs.

Interpretation: The variability of waiting time to first treatment for patients with prostate, breast, lung or colorectal cancer decreased between 2002 and 2012, which indicates improvements in equity in access to cancer care. This trend aligns with provincial efforts to improve access to and the efficiency of cancer care treatment in Ontario. The lack of consistent decreases in median waiting time highlights the need to identify improvement opportunities for cancer type-treatment type pairs with increasing median waiting times.

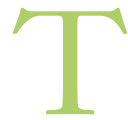
here is considerable public concern about cancer and the quality of service that patients with the disease receive. It is predicted that cancer will develop in 2 in 5 Canadians in their lifetime, and most of these cases will be cancers of prostate, breast, lung or colorectal origin. ${ }^{1}$ In recent years, cancer has been the leading cause of death in Canada. ${ }^{2}$ In 2010, these 4 cancer types accounted for an important proportion of cancer deaths: prostate $5 \%$, breast $7 \%$, lung $27 \%$ and colorectal $12 \% .^{3}$ Qualitative research has shown that patient-perceived waiting time, defined as the period between symptom onset and first treatment, plays an important role in patient satisfaction. ${ }^{4}$ An extended waiting time can be associated with substantial mental strain for patients and their family members, and may also worsen the prognosis..$^{5-7}$ In a UK study involving patients with prostate cancer, extended treatment waiting times led to growth in cross-sectional tumour size up to $373 \%$, and the disease became medically incurable in $21 \%$ of the patients. ${ }^{8}$
Although components of perceived waiting time may be unavoidable or deliberate in some cases, it is generally accepted that waiting time should be shortened as much as possible. ${ }^{9-12}$ As interest increases in integrating patientreported outcomes into assessment of the quality of care in oncology, ${ }^{13,14}$ patient-reported perceived waiting time is used as a measure to assess the quality of care from the patient's perspective. ${ }^{15}$

Competing interests: Alexander Louie has received honoraria unrelated to this work from Varian Medical Systems. Gregory Zaric has received consulting fees from Amgen and executive education fees from Bayer, both unrelated to this work. No other competing interests were declared.

This article has been peer reviewed.

Correspondence to: Amir Rastpour, amir.rastpour@uoit.ca

CMAJ Open 2018. DOI:10.9778/cmajo.20170118 
Although perceived waiting time plays a key role in patient satisfaction, most studies examining waiting time have focused only on parts of the perceived waiting time, namely, family physician referral to specialist visit ${ }^{16}$ and diagnosis to treatment. ${ }^{17}$ Studies that have focused on perceived waiting time were based mainly on surveys and therefore had small samples. ${ }^{4,15}$ The purpose of this work was to use administrative data with large samples to study perceived waiting time among patients with cancer. We analyzed the variability and the median of perceived waiting time for patients with the 4 most prevalent cancer types (prostate, breast, lung and colorectal) in Ontario.

\section{Methods}

\section{Data sources}

We used retrospective administrative data from Ontario to investigate the change in waiting times from when a patient sought care until the first treatment (chemotherapy, radiotherapy or surgery) for the 4 most prevalent cancer types (prostate, breast, lung and colorectal) between 2002 and 2012. The Ontario Cancer Registry is a data set that contains details for $98 \%$ of incident cases of malignant disease in Ontario. ${ }^{18,19}$ We used the registry to identify patients with prostate, breast, lung or colorectal cancer during the study period and followed them until the end of 2013 to ensure that those who received the diagnosis in 2012 had a minimum of 1 year of follow-up. In Ontario, physician services are covered through the universal Ontario Health Insurance Plan (OHIP), and the OHIP data set covers $94 \%$ of physician services provided to the population. ${ }^{20} \mathrm{We}$ linked the OHIP data set to the Ontario Cancer Registry using encrypted unique patient identifiers to track all relevant diagnostic and treatment services. Data were provided by the Ontario Cancer Data Linkage Project (cd-link), an initiative of the Ontario Institute for Cancer Research/Cancer Care Ontario Health Services Research Program, whereby risk-reduced coded data from the Institute for Clinical Evaluative Sciences Data Repository are provided directly to researchers with the protections of a comprehensive data use agreement.

\section{Variables}

We calculated variables of interest as follows. For any given cancer type, we searched through all OHIP records of each patient and recorded the earliest billing date that a potentially diagnostic procedure took place on the cancer site (and the diagnosis outcome indicated disease in the cancer site). We defined that date as the care-seeking date. For example, if a patient had a diagnostic radiology procedure, recorded as fee code X090, and the outcome was an issue related to the bronchus or lung, recorded as OHIP diagnosis code 162, we recorded the radiotherapy date as the care-seeking date. We then identified the first billing date after the care-seeking date on which a treatment procedure (e.g., major decortication of lung for empyema or tumour, fee code M135) was carried out at the cancer site and referred to that date as the first treatment date. The first treatment intervention could be chemo- therapy, radiotherapy or surgery. We calculated the perceived waiting time as the period between the care-seeking date and the first treatment date.

\section{Primary and secondary outcomes}

Our primary outcome was variability in waiting time, which we measured using the coefficient of variation (CV) of waiting times and the Gini coefficient of waiting times. The CV is a commonly used measure in engineering, physics and manufacturing. In particular, it is an important measure of process variability in manufacturing settings, where a small $\mathrm{CV}$ indicates a more consistent process. ${ }^{21-23}$ The Gini coefficient is often used to measure income distribution and other social development indicators. ${ }^{24}$ Both measures are unitless and have relative strengths and weaknesses. ${ }^{24,25}$ For example, the $\mathrm{CV}$ treats waiting time inequalities throughout the waiting time spectrum the same, whereas the Gini coefficient is more sensitive to waiting time inequalities in the middle of the spectrum than those in the tails. ${ }^{24} \mathrm{We}$ also examined median waiting times as a proxy for the quality of service that patients received.

\section{Statistical analysis}

We grouped patients based on cancer type, treatment type and the year of the care-seeking date. For each cohort, we calculated the $\mathrm{CV}$ and Gini coefficient of waiting times and the median waiting time. As a robustness check, for censored observations (i.e., first treatment was not observed), we estimated the median and $\mathrm{CV}$ of waiting times for each cancer type by fitting a Weibull survival model. ${ }^{26,27}$ We obtained a line of best fit using linear regression to determine the significance of trends over time for each performance measure. We performed all analyses with SAS version 9.3 (SAS Institute).

\section{Ethics approval}

This study was approved by the University of Western Ontario Research Ethics Board.

\section{Results}

Between 2002 and 2012, 348110 patients received a diagnosis of prostate, breast, lung or colorectal cancer in Ontario. We excluded 379 patients $(0.1 \%)$ who did not have any records in the OHIP data set, resulting in a study cohort of 347731 patients. A total of 95438 patients (27.4\%), had prostate cancer, $89161(25.6 \%)$ had breast cancer, 82454 (23.7\%) had lung cancer, and 80678 (23.2\%) had colorectal cancer.

For each cancer type-treatment type pair, we calculated the number of patients who received that particular intervention as their first treatment in any given year (Supplementary Figure 1, Appendix 1, available at www.cmajopen.ca/ content/6/2/E227/suppl/DC1). Surgery was the most common first treatment for patients with prostate $(n=32814$ [52.7\%]), breast $(n=68694[84.7 \%])$ and colorectal $(n=$ $53704[82.5 \%]$ ) cancer. Patients with lung cancer most com- 
monly received radiotherapy (with or without chemotherapy) as their first treatment ( $n=23063$ [47.3\%]).

The median perceived waiting time for each cancer type by treatment over the study period is shown in Figure 1. There was a trend toward increasing median waiting time per year for surgery for all 4 cancer types over the study period: 2.6 days for prostate cancer, 1.9 days for breast cancer, 1.5 days for lung cancer and 0.4 days for colorectal cancer (Table 1 ).

There was a trend toward decreasing median waiting time per year for radiotherapy for prostate and breast cancer, but there was no significant change in median waiting time over the study period for lung and colorectal cancer; the negative trend was -2.8 days for prostate cancer and -1.6 days for breast cancer and -1.0 day for colorectal cancer. There was a trend toward decreasing median waiting time per year for chemotherapy for all cancer types except lung cancer, for which there was no significant change in median waiting time over the study period; the negative trend was -84.0 days for prostate cancer, -3.3 days for breast cancer and -1.8 days for colorectal cancer.

\section{A. Prostate cancer}

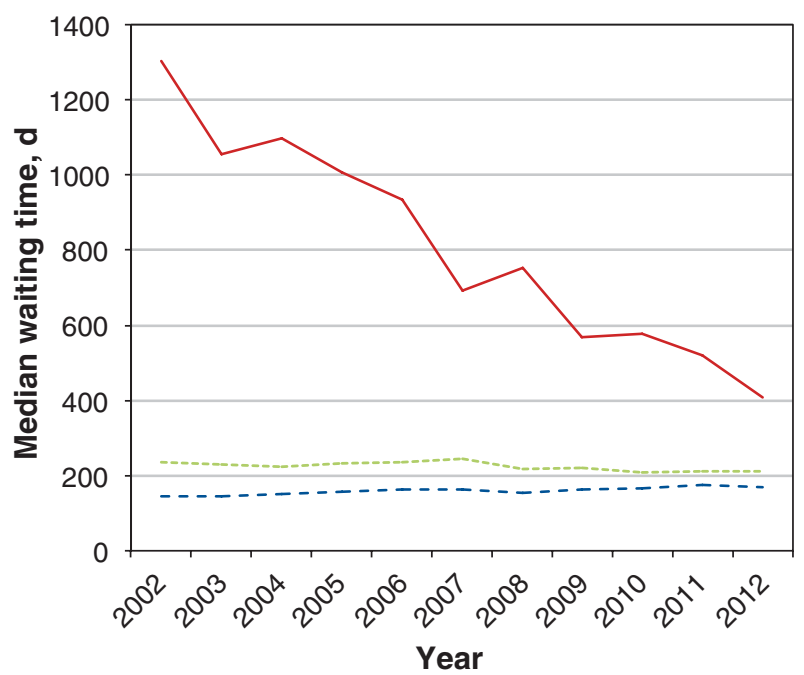

\section{Lung cancer}

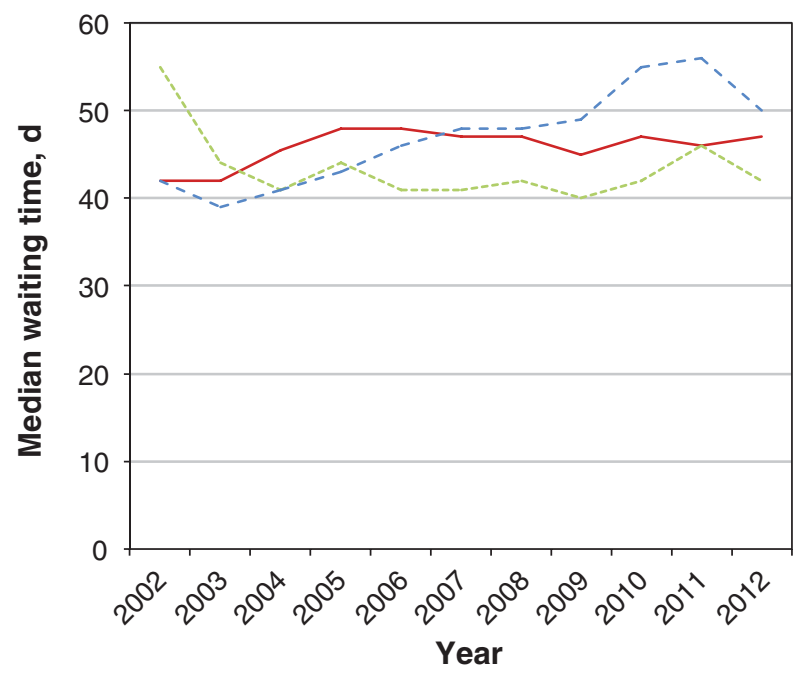

\section{B. Breast cancer}

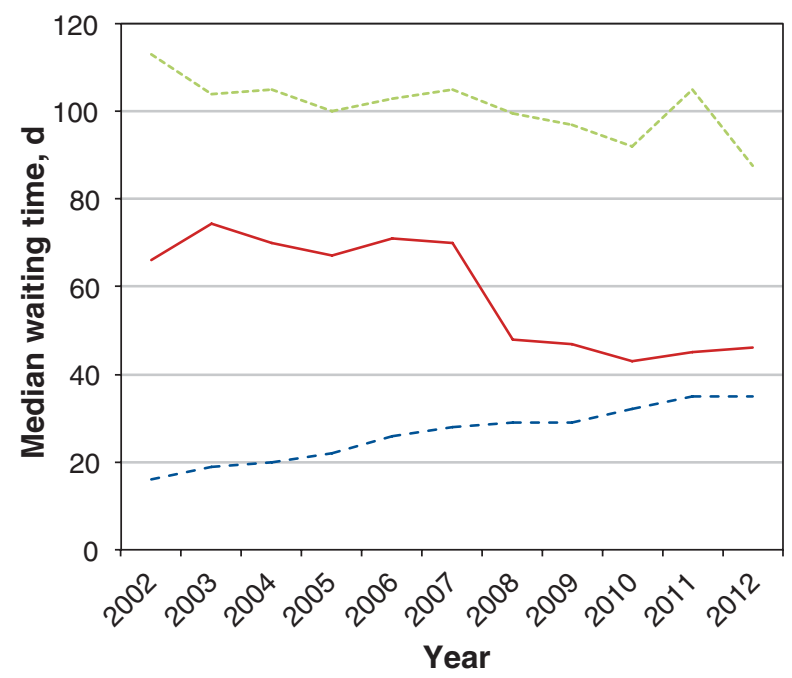

\section{Colorectal cancer}

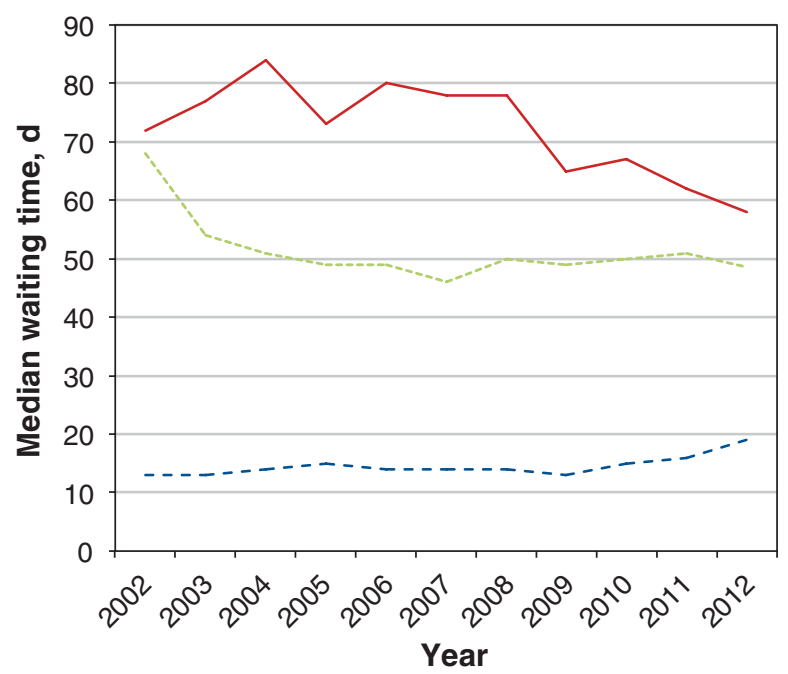

Figure 1: Median perceived waiting time by first treatment. 


\begin{tabular}{|c|c|}
\hline \multicolumn{2}{|c|}{ Table 1: Trend analysis for median waiting time } \\
\hline $\begin{array}{l}\text { Cancer type; first } \\
\text { treatment }\end{array}$ & Slope $^{*}(95 \% \mathrm{Cl})$ \\
\hline \multicolumn{2}{|l|}{ Prostate } \\
\hline Chemotherapy & $-84.045(-98.447$ to -69.644$)$ \\
\hline Radiotherapy & $-2.782(-4.711$ to -0.853$)$ \\
\hline Surgery & 2.605 (1.636 to 3.573$)$ \\
\hline \multicolumn{2}{|l|}{ Breast } \\
\hline Chemotherapy & $-3.291(-4.788$ to -1.794$)$ \\
\hline Radiotherapy & $-1.564(-2.627$ to -0.501$)$ \\
\hline Surgery & 1.927 (1.698 to 2.156$)$ \\
\hline \multicolumn{2}{|l|}{ Lung } \\
\hline Chemotherapy & $0.35(-0.054$ to 0.754$)$ \\
\hline Radiotherapy & $-0.555(-1.414$ to 0.305$)$ \\
\hline Surgery & $1.491(0.946$ to 2.036$)$ \\
\hline \multicolumn{2}{|l|}{ Colorectal } \\
\hline Chemotherapy & $-1.809(-3.086$ to -0.532$)$ \\
\hline Radiotherapy & $-1.014(-2.1$ to 0.073$)$ \\
\hline Surgery & 0.373 (0.09 to 0.655$)$ \\
\hline \multicolumn{2}{|c|}{$\begin{array}{l}\text { Note: } \mathrm{Cl}=\text { confidence interval. } \\
\text { "The slope term indicates the annual change in the median number of days until } \\
\text { first treatment for each cancer-treatment type pair. For example, among patients } \\
\text { with colorectal cancer who received chemotherapy as their first treatment, the } \\
\text { median time to first treatment decreased by } 1.81 \text { days per year over the study } \\
\text { period. }\end{array}$} \\
\hline
\end{tabular}

Figure 2 and Figure 3 show the CV and Gini coefficient of waiting times, respectively, for each cancer type by treatment. The slope of the fitted trend line for both metrics is presented in Table 2. Both measures of waiting time variability had decreasing trends for all cancer type-treatment type pairs over the study period except for the Gini coefficient for breast cancer-radiotherapy. The maximum average decrease in the $\mathrm{CV}$ was observed for waiting times for surgery for patients with breast cancer, for which the average $\mathrm{CV}$ decreased more than $30 \%$ each year. Results for the median and CV, stratified by cancer type, were qualitatively similar when we accounted for censoring using a parametric survival model (data not shown).

\section{Interpretation}

In this study of waiting times for the 4 most prevalent cancer types in Ontario, we observed a continuous decrease between 2002 and 2012 in the variability of waiting times from when patients sought care to their first treatment. In Ontario, Cancer Care Ontario is the agency that is responsible for improving cancer services and, in a publicly funded universal health care system, acts as the government's advisor on the delivery of health care services for patients with cancer. A 2004 Cancer Care Ontario report mentioned "streamlining of clinical services [for cancer patients]" as one of achievements of the initiatives implemented by the agency and outlined further actions to be taken in the future. ${ }^{28}$ In a more recent report, Cancer Care Ontario stated that "patients' access to care and their health outcomes should not depend on demographic characteristics or where they live" and cited the Aboriginal Cancer Strategy as an example of initiatives to better serve traditionally underserved populations. ${ }^{14}$ We hypothesize that these efforts may help explain the continuous decrease in the variability of waiting times.

Unlike the variability of the waiting times, however, the median waiting times did not always show a decreasing trend. The median trend increased for patients whose first treatment was surgery, across all 4 cancer types, and for patients with lung cancer whose first treatment was chemotherapy. All other patients either experienced a decreasing trend or did not have significant changes in trends.

We used the CV and Gini coefficient as measures of variability in waiting times. The 2 measures revealed similar trends in variability of waiting times.

Variations in waiting times for different patient cohorts have been viewed as an indication of equity. ${ }^{29}$ Thus, we interpret continuous decreases in the variability of waiting times as improvements in the equity in waiting times, which is aligned with other health care policies in Canada, such as principles suggested by the Canadian Medical Association and the Canadian Nurses Association that listed "equitable access to quality care" as one of the principles for improvement in the Canadian health care system..$^{30}$ Other countries, such as Chile, Germany, Greece, New Zealand, Slovenia, Sweden and the United Kingdom, use equal access to health care and equal use of health care services as elements of equitable access to health care and have policies for improving these elements. ${ }^{31}$

There is a lack of consensus on the definition of waiting time. ${ }^{32,33} \mathrm{~A}$ common alternative definition is the time from the date of diagnosis (clinical or pathological) to the first treatment. Using this definition, Bardell and colleagues ${ }^{33}$ found that the median waiting time in Ontario from diagnosis to surgery for prostate, breast, lung and colorectal cancer had an increasing trend from 1984 to 2000, consistent with our results. Another study showed that median waiting times from diagnosis to radiotherapy steadily increased in Ontario between 1982 and $1991 .{ }^{17}$ In the current study, the $\mathrm{CVs}$ of waiting time for chemotherapy for patients with colorectal cancer were consistently smaller than those for patients with breast cancer, which agrees with a previous finding that there was less variation in the time from diagnosis to adjuvant chemotherapy for patients with colon cancer than for those with breast cancer in Ontario in 2009. ${ }^{34}$

Our study does not account for changes over time in standard management that may have caused differences in waiting times. As an example, we observed a dramatic decrease in the median waiting time for chemotherapy as the first treatment for patients with prostate cancer, from 1303 days in 2002 to 406 days in 2012. This finding can be attributed to the fact that chemotherapy was established only recently as a standard first-line treatment for certain patients with metastatic prostate 
A. Prostate cancer

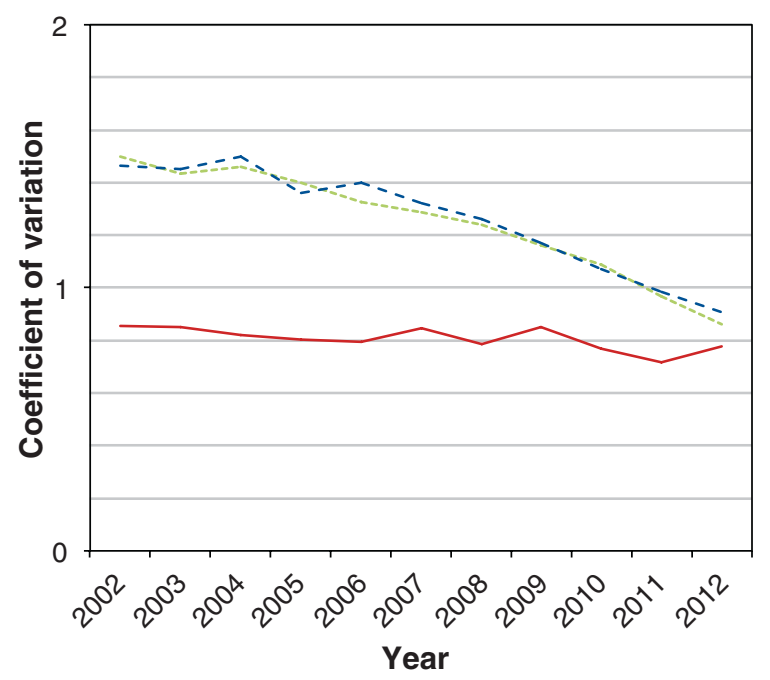

C. Lung cancer

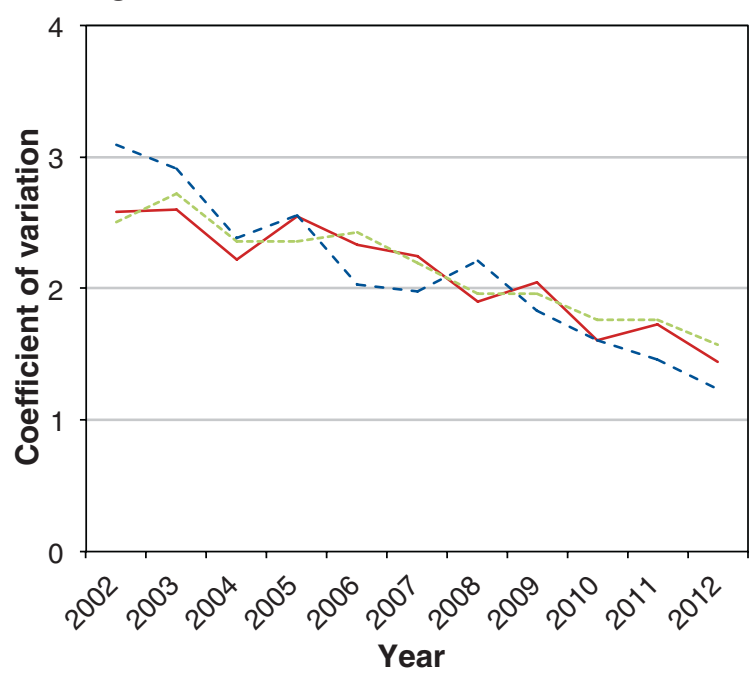

B. Breast cancer

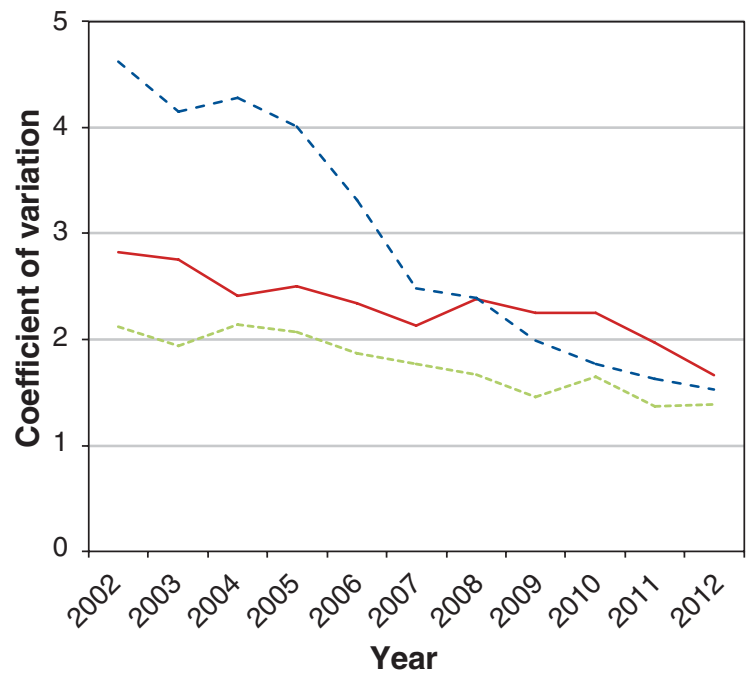

D. Colorectal cancer

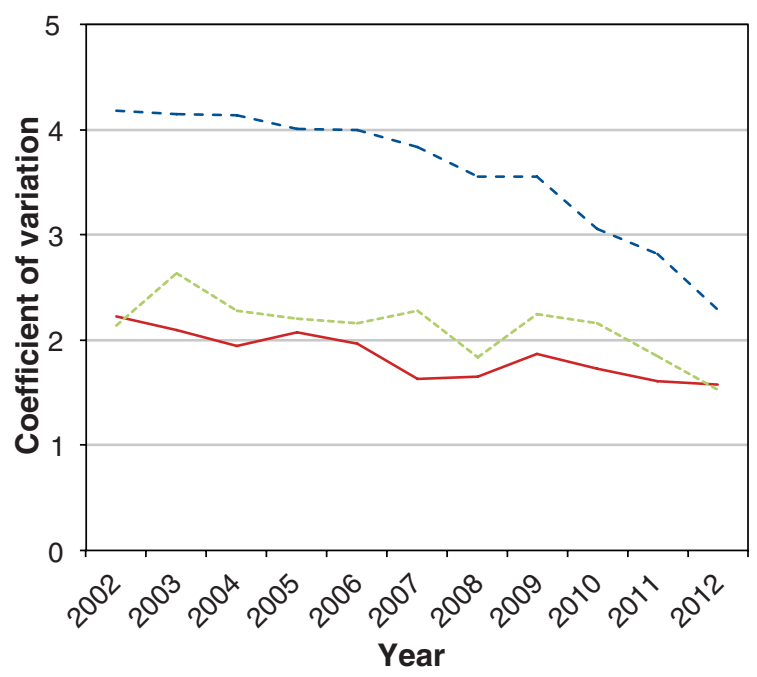

- Chemotherapy -------- Radiotherapy - - - - Surgery

Figure 2: Coefficient of variation of waiting times.

cancer. ${ }^{35,36}$ Before this, chemotherapy was used primarily when prostate cancer was hormone refractory, which would often occur over the course of years. ${ }^{37}$

\section{Strengths and limitations}

We propose an approximation for the perceived waiting time that allowed us to use administrative data sets to analyze waiting time. Our focus on perceived waiting time is aligned with research and policies that stress the importance of studying the entire waiting time rather than parts of it, such as referral to specialist visit or diagnosis to treatment. ${ }^{4,38}$ Despite the importance of analysis of perceived waiting time, the literature contains few relevant studies, all of which are based on small samples. ${ }^{12,31} \mathrm{We}$ addressed the issue of small samples by using administrative data sets. We also introduce the $\mathrm{CV}$ as a measure of cancer care equity, and we found similar trends in waiting time variability using 2 different measures. 


\section{A. Prostate cancer}

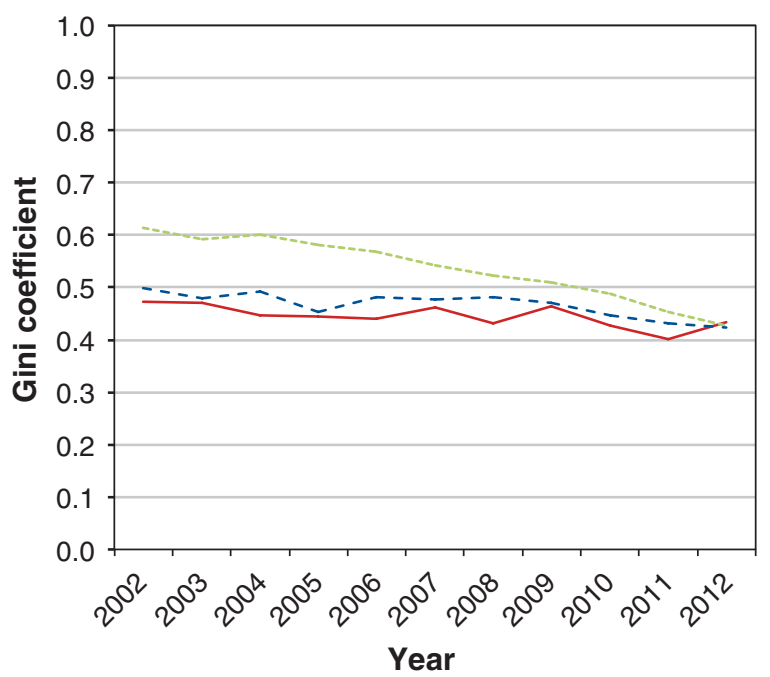

\section{Lung cancer}

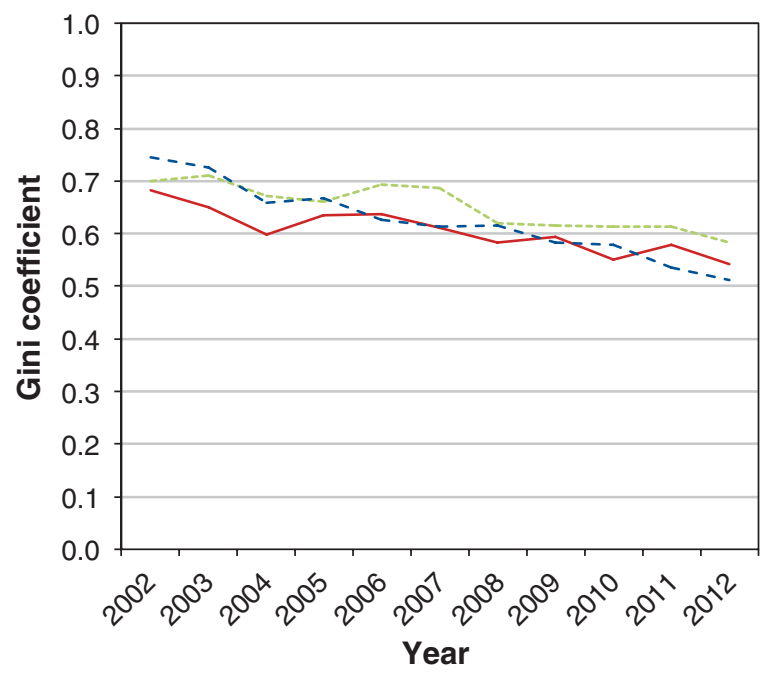

\section{B. Breast cancer}

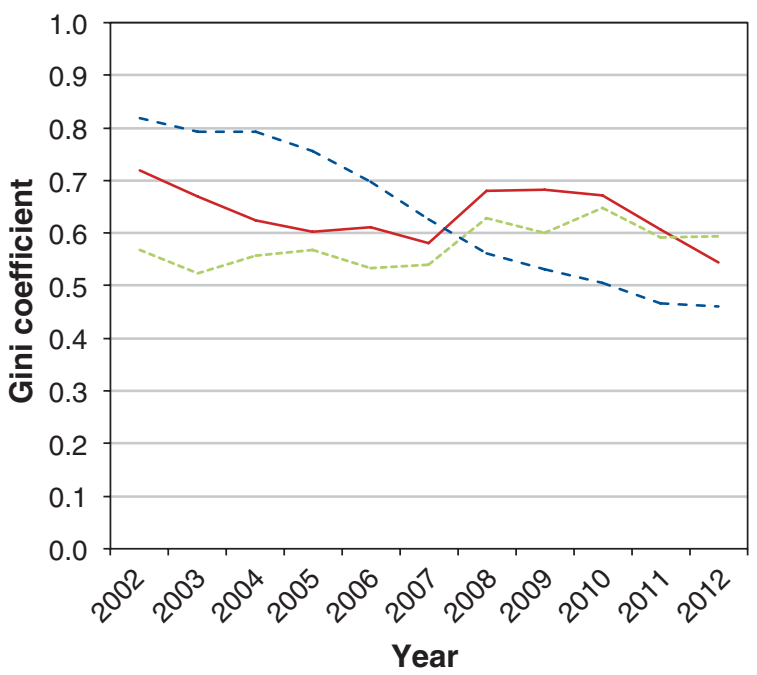

D. Colorectal cancer

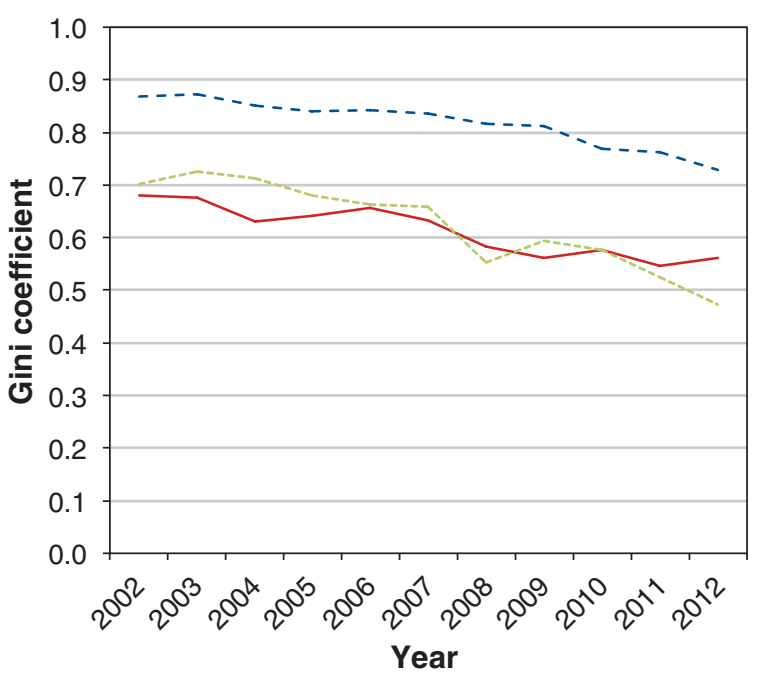

Figure 3: Gini coefficient of waiting times.

This study had limitations. We focused on the 4 most prevalent cancer types because they are of highest public health interest and they encompass different management strategies, treatments and courses. We could not include sociodemographic and socioeconomic factors in analysis and could not include the patients' characteristics owing to the lack of these data. However, our regression analyses were conducted at the aggregate (provincial) level, and it is not clear that sociodemographic covariates, which are at the individual level, would have been useful at that level of analysis. At the end of the follow-up year, we had 7718 censored patients, and we used a Weibull survival model to perform a robustness check. We used the care-seeking date as a proxy for the date of symptom onset, as the latter was not available in our data set. This may be a limitation in most studies of waiting times using administrative data. We did not have information about potential waiting reasons such as watchful waiting, which is recommended in low-risk cancers (especially of the lung). However, we have no reason to believe that the prevalence of this type of treatment changed over time. We used data from Ontario, and our findings may 


\begin{tabular}{|c|c|c|}
\hline \multirow{2}{*}{$\begin{array}{l}\text { Cancer type; first } \\
\text { treatment }\end{array}$} & \multicolumn{2}{|c|}{ Slope $^{*}(95 \%$ Cl) } \\
\hline & $\mathrm{CV}$ & Gini coefficient \\
\hline \multicolumn{3}{|l|}{ Prostate } \\
\hline Chemotherapy & $-0.009(-0.016$ to -0.002$)$ & $-0.004(-0.008$ to -0.001$)$ \\
\hline Radiotherapy & $-0.061(-0.072$ to -0.051$)$ & $-0.018(-0.021$ to -0.016$)$ \\
\hline Surgery & $-0.058(-0.072$ to -0.045$)$ & $-0.006(-0.009$ to -0.003$)$ \\
\hline \multicolumn{3}{|l|}{ Breast } \\
\hline Chemotherapy & $-0.089(-0.122$ to -0.057$)$ & $-0.007(-0.018$ to 0.004$)$ \\
\hline Radiotherapy & $-0.08(-0.104$ to -0.057$)$ & $0.008(0.001$ to 0.014$)$ \\
\hline Surgery & $-0.347(-0.407$ to -0.287$)$ & $-0.041(-0.047$ to -0.036$)$ \\
\hline \multicolumn{3}{|l|}{ Lung } \\
\hline Chemotherapy & $-0.113(-0.147$ to -0.08$)$ & $-0.012(-0.016$ to -0.007$)$ \\
\hline Radiotherapy & $-0.105(-0.129$ to -0.081$)$ & $-0.012(-0.016$ to -0.008$)$ \\
\hline Surgery & $-0.17(-0.207$ to -0.133$)$ & $-0.021(-0.025$ to -0.018$)$ \\
\hline \multicolumn{3}{|l|}{ Colorectal } \\
\hline Chemotherapy & $-0.06(-0.085$ to -0.035$)$ & $-0.014(-0.018$ to -0.01$)$ \\
\hline Radiotherapy & $-0.062(-0.109$ to -0.015$)$ & $-0.024(-0.03$ to -0.018$)$ \\
\hline Surgery & $-0.176(-0.228$ to -0.124$)$ & $-0.013(-0.017$ to -0.01$)$ \\
\hline \multicolumn{3}{|c|}{$\begin{array}{l}\text { Note: } \mathrm{Cl}=\text { confidence interval, } \mathrm{CV}=\text { coefficient of variation. } \\
{ }^{\circ} \text { The slope term indicates the annual change in the } \mathrm{CV} \text { and the Gini coefficient of the number of days until first } \\
\text { treatment for each cancer-treatment type pair. For example, among patients with colorectal cancer who received } \\
\text { chemotherapy as their first treatment, the } \mathrm{CV} \text { of the time to first treatment decreased by } 0.06 \text { per year over the } \\
\text { study period. }\end{array}$} \\
\hline
\end{tabular}

not be applicable to other jurisdictions. Furthermore, our outcomes may not be directly applicable to time frames outside our study period owing to changes in demographic characteristics, cancer incidence, treatment options and treatment guidelines.

\section{Conclusion}

We found decreasing trends between 2002 and 2012 in the variability of waiting times from first care seeking to first treatment for the 4 most prevalent cancer types (prostate, breast, lung and colorectal) in Ontario for all cancer type-treatment type pairs. This suggests improvements in equity in access to care. However, we observed both decreasing and increasing trends in median waiting times. Specifically, the median waiting time for surgery as first treatment increased significantly for all cancer types. This highlights the need to identify improvement opportunities for cancer type-treatment type pairs with increasing median waiting times.

\section{References}

1. Canadian Cancer Society's Advisory Committee on Cancer Statistics. Canadian cancer statistics 2016. Toronto: Canadian Cancer Society; 2016.

2. Leading causes of death and hospitalization in Canada. Ottawa: Public Health Agency of Canada; 2016. Available: www.phac-aspc.gc.ca/publicat/lcd-pcd97/ index-eng.php (accessed 2017 May 20).

3. Canadian Cancer Society's Advisory Committee on Cancer Statistics. Canadian cancer statistics 2015. Toronto: Canadian Cancer Society; 2015.

4. Mathews M, Ryan D, Bulman D. What does satisfaction with wait times mean to cancer patients? BMC Cancer 2015;15:1017.
5. Miles A, McClements P, Steele R, et al. Perceived diagnostic delay and cancer-related distress: a cross-sectional study of patients with colorectal cancer. Psychooncology 2017;26:29-36.

6. Rutqvist L. Waiting times for cancer patients - a "slippery slope" in oncology. Acta Oncol 2006;45:121-3.

7. Risberg T, Norum J, Wist E. Diagnostic delay causes more psychological distress in female than in male cancer patients. Anticancer Res 1996;16:995-9.

8. O'Rourke N, Edwards R. Lung cancer treatment waiting times and tumour growth. Clin Oncol (R Coll Radiol) 2000;12:141-4.

9. Myrdal G, Lambe M, Hillerdal G, et al. Effect of delays on prognosis in patients with non-small cell lung cancer. Thorax 2004;59:45-9.

10. Salomaa ER, Sallinen S, Hiekkanen H, et al. Delays in the diagnosis and treatment of lung cancer. Chest 2005;128:2282-8.

11. Sainsbury R, Johnston C, Haward B. Effect on survival of delays in referral of patients with breast-cancer symptoms: a retrospective analysis. Lancet 1999; 353:1132-5.

12. Robinson E, Mohilever J, Zidan J, et al. Colorectal cancer: incidence, delay in diagnosis and stage of disease. Eur 7 Cancer Clin Oncol 1986;22:157-61.

13. Basch E, Snyder C, McNiff K. Patient-reported outcome performance measures in oncology. 7 Oncol Pract 2014;10:209-11.

14. Ontario cancer plan IV: 2015-2019. Toronto: Cancer Care Ontario; 2015.

15. Ellis PM, Vandermeer R. Delays in the diagnosis of lung cancer. 7 Thorac Dis 2011;3:183-8.

16. Thind A, Stewart M, Manuel D, et al. What are wait times to see a specialist? An analysis of 26942 referrals in southwestern Ontario. Healthc Policy 2012;8: 80-91.

17. Mackillop WJ, Fu H, Quirt C, et al. Waiting for radiotherapy in Ontario. Int 7 Radiat Oncol Biol Phys 1994;30:221-8.

18. Robles SC, Marrett D, Clarke A, et al. An application of capture-recapture methods to the estimation of completeness of cancer registration. 7 Clin Epidemiol 1988;41:495-501.

19. Clarke EA, Marrett LD, Kreiger N. Appendix 3 (c) - Cancer registration in Ontario: a computer approach. In: Jensen OM, Parkin R, MacLennan R, editors. Cancer registration: principles and methods. Lyon (France): International Agency for Research on Cancer; 1991:246-57.

20. Improving bealth care data in Ontario. ICES investigative report. Toronto: Institute for Clinical Evaluative Sciences; 2005. 
21. Aja-Fernández S, Alberola-Lopez C. On the estimation of the coefficient of variation for anisotropic diffusion speckle filtering. IEEE Trans Image Process 2006;15:2694-701.

22. Hillier F, So K. The effect of the coefficient of variation of operation times on the allocation of storage space in production line systems. IIE Trans 1991;23:198-206.

23. Kordonsky IB, Gertsbakh K. Multiple time scales and the lifetime coefficient of variation: engineering applications. Lifetime Data Anal 1997;3:139-56.

24. Atkinson A. On the measure of inequality. 7 Econ Theory 1969;2:244-63.

25. De Maio FG. Income inequality measures. 7 Epidemiol Community Health 2007; 61:849-52.

26. Hosmer DW, Lemeshow S, May S. Applied survival analysis: regression modeling of time-to-event data. Hoboken (NJ): John Wiley \& Sons; 2011.

27. Zhang Z. Parametric regression model for survival data: Weibull regression model as an example. Ann Transl Med 2016;4:484.

28. Ontario cancer plan 2005-2008. Toronto: Cancer Care Ontario; 2004.

29. Cooper ZN, McGuire A, Jones S, et al. Equity, waiting times, and NHS reforms: retrospective study. BM7 2009;339:b3264.

30. Principles to guide health care transformation in Canada. Ottawa: Canadian Medical Association and Canadian Nurses Association; 2011.

31. Oliver A, Mossialos E. Equity of access to health care: outlining the foundations for action. 7 Epidemiol Community Health 2004:58:655-8.

32. Sanmartin C. Toward standard definitions for waiting times. Healthc Manage Forum 2003;16:49-53.

33. Bardell T, Belliveau P, Kong W, et al. Waiting times for cancer surgery in Ontario: 1984-2000. Clin Oncol (R Coll Radiol) 2006;18:401-9.

34. Kaizer L, Krzyzanowska MK, Hertz S, et al. Patient-centered wait time measurement in Ontario. 7 Clin Oncol 2012;30(Suppl):233.

35. James ND, Sydes M, Clarke N, et al. Systemic therapy for advancing or metastatic prostate cancer (STAMPEDE): a multi-arm, multistage randomized controlled trial. BfU Int 2009;103:464-9.

36. James ND, Sydes MR, Mason MD, et al. Docetaxel and/or zoledronic acid for hormone-naïve prostate cancer: first overall survival results from STAMPEDE (NCT00268476). f Clin Oncol 2015;33(Suppl):5001.

37. Tannock IF, de Wit R, Berry W, et al. Docetaxel plus prednisone or mitoxantrone plus prednisone for advanced prostate cancer. NEngl f Med 2004;351:1502-12.

38. Wait times for priority procedures in Canada, 2017. Ottawa: Canadian Institute for Health Information; 2017.
Affiliations: Faculty of Business and Information Technology (Rastpour), University of Ontario Institute of Technology, Oshawa, Ont.; Ivey Business School (Begen, Zaric), University of Western Ontario; Department of Radiation Oncology (Louie), London Regional Cancer Program, University of Western Ontario, London, Ont.

Contributors: Amir Rastpour, Mehmet Begen and Gregory Zaric contributed to the study conception and design. Mehmet Begen acquired the data, and Amir Rastpour and Alexander Louie analyzed the data. Alexander Louie provided clinical correlation in the interpretation of the results. All of the authors contributed to interpreting the data and writing the manuscript, gave final approval of the version to be published and agreed to be accountable for all aspects of the work.

Funding: This work was funded by grant RGPIN/04089-2017 from the Natural Sciences and Engineering Research Council of Canada and was supported through funding to the Institute for Clinical Evaluative Sciences from an annual grant by the Ontario Ministry of Health and LongTerm Care and the Ontario Institute for Cancer Research.

Disclaimer: This study was supported through provision of data by the Institute for Clinical Evaluative Sciences (ICES) and Cancer Care Ontario (CCO). The opinions, results and conclusions reported in this paper are those of the authors. No endorsement by the ICES, the CCO, the Ontario Institute for Cancer Research or the government of Ontario is intended or should be inferred. Parts of this material are based on data and information compiled and provided by the Canadian Institute for Health Information (CIHI). However, the analyses, conclusions, opinions and statements expressed herein are those of the authors and not necessarily those of the CIHI.

Supplemental information: For reviewer comments and the original submission of this manuscript, please see www.cmajopen.ca/content/6/2/ E227/suppl/DC1. 